\title{
BMJ Open Discontinuation of non-Vitamin K antagonist oral anticoagulants in patients with non-valvular atrial fibrillation: a population-based cohort study using primary care data from The Health Improvement Network in the UK
}

\author{
Ana Ruigómez, ${ }^{1}$ Pareen Vora, ${ }^{2}$ Yanina Balabanova, ${ }^{2}$ Gunnar Brobert, ${ }^{3}$ \\ Luke Roberts, ${ }^{4}$ Samuel Fatoba, ${ }^{5}$ Oscar Fernandez, ${ }^{1}$ Luis Alberto García Rodríguez ${ }^{1}$
}

To cite: Ruigómez A, Vora P, Balabanova Y, et al. Discontinuation of nonVitamin $\mathrm{K}$ antagonist oral anticoagulants in patients with non-valvular atrial fibrillation: a population-based cohort study using primary care data from The Health Improvement Network in the UK. BMJ Open 2019;9:e031342. doi:10.1136/ bmjopen-2019-031342

- Prepublication history and additional material for this paper are available online. To view please visit the journal (http:// dx.doi.org/10.1136/bmjopen2019-031342).

Received 30 April 2019 Revised 06 August 2019 Accepted 23 September 2019

Check for updates

(C) Author(s) (or their employer(s)) 2019. Re-use permitted under CC BY-NC. No commercial re-use. See rights and permissions. Published by BMJ.

For numbered affiliations see end of article.

Correspondence to

Dr Ana Ruigómez;

aruigomez@ceife.es

\section{ABSTRACT}

Objective To determine discontinuation rates, patterns of use and predictors of discontinuation of non-vitamin $\mathrm{K}$ antagonist oral anticoagulants (NOACs) among patients with non-valvular atrial fibrillation (NVAF) in the first year of therapy.

Design Population-based cohort study.

Setting UK primary care.

Population 11481 patients with NVAF and a first prescription (index date) for apixaban, dabigatran or rivaroxaban (January 2012 to December 2016) with at least 1 year of follow-up and at least one further NOAC prescription in the year following the index date were identified. 1 year rates and patterns of discontinuation were described.

Primary and secondary outcome measures Outcome measures were the percentage of patients who, in the first year from starting NOAC therapy, discontinued with their oral anticoagulant $(\mathrm{OAC})$ therapy (discontinuation was defined as a gap in OAC therapy of $>30$ days); switched OAC within 30 days; discontinued and reinitiated OAC therapy. Predictors of discontinuation were also evaluated. Results 1 year discontinuation rates according to the index NOAC were $26.1 \%$ for apixaban, $40.0 \%$ for dabigatran and $29.6 \%$ for rivaroxaban. Reinitiation rates were $18.1 \%$ for apixaban, $21.7 \%$ for dabigatran and $17.3 \%$ for rivaroxaban, and switching rates were $2.8 \%$ for apixaban, $8.8 \%$ for dabigatran and $4.9 \%$ for rivaroxaban. More than $93 \%$ of reinitiations were with the index NOAC. Patients starting on dabigatran were more likely to switch OAC therapy than those starting on apixaban; ORs 4.28 (95\% Cl 3.24 to 5.65) for dabigatran and $1.89(95 \% \mathrm{Cl}$ 1.49 to 2.39 ) for rivaroxaban. Severely reduced renal function was a predictor of any discontinuation, OR 1.77 (95\% Cl 1.28 to 2.44).

Conclusion While the majority of patients with NVAF in the UK initiating NOAC treatment received continuous therapy in the first year of treatment, a substantial proportion of patients experienced gaps in treatment
Strengths and limitations of this study

- Our study is the largest to evaluate non-vitamin $\mathrm{K}$ antagonist oral anticoagulant (NOAC) discontinuation rates among patients with non-valvular atrial fibrillation in the UK.

- The long study period enabled contemporary patterns of use between individual NOACs to be compared.

- The use of a validated primary care database representative of the UK demographic means our results are generalisable to the UK general population.

- We were unable to evaluate reasons for NOAC discontinuation/switching because this information is often entered as free text rather than as coded entries.

leaving them less protected against thromboembolism during these periods.

\section{INTRODUCTION}

Atrial fibrillation (AF) is a common cardiac arrhythmia encountered in clinical practice with an estimated prevalence of around 3\% among adults aged 20 years or older. ${ }^{12}$ Left untreated, it is a significant risk factor for stroke and other morbidity, and therefore requires management with oral anticoagulant (OAC) therapy to mitigate risk. ${ }^{34}$

In the UK, the non-vitamin $\mathrm{K}$ antagonist oral anticoagulants (NOACs)—apixaban, edoxaban, dabigatran and rivaroxaban-are recommended as treatment options for stroke prevention in patients with $\mathrm{AF}^{4}$ and are now more commonly prescribed than warfarin in this patient population. ${ }^{56}$ Continuation with 
therapy in the long term is advocated in most patients. ${ }^{78}$ NOACs have clear advantages over vitamin $\mathrm{K}$ antagonists (VKAs) such as warfarin. In addition to their favourable benefit-risk profile and fewer food-drug and drug-drug interactions, the fixed-dose and predictable pharmacokinetics of these medications removes the need for routine therapeutic coagulation monitoring (and thereby potentially fewer visits to healthcare professionals) or dose adjustment for body weight. However, less stringent monitoring requirements could mean that identification of patients discontinuing with treatment is more challenging, ${ }^{9}$ and this is important because discontinuation of therapy among patients with $\mathrm{AF}$ is associated with an increased risk of stroke and all-cause mortality. ${ }^{9}{ }^{10}$ Owing to the short half-life of NOACs, ${ }^{11}$ their use should be uninterrupted to maintain the drug in the therapeutic range and thereby providing adequate thromboembolic protection.

Since the introduction of NOACs in clinical practice, many studies have evaluated patient discontinuation rates; ${ }^{12-21}$ however, several have been limited in size and follow-up duration and/or restricted to only one or two individual NOACs. ${ }^{12} 1315$ 18-20 22 We conducted a large population-based cohort study to evaluate the frequency and predictors of discontinuation of NOACs among firsttime NOAC users with non-valvular atrial fibrillation (NVAF), as well as subsequent detailed patterns of OAC therapy use during the first year of treatment in the UK between January 2012 and December 2016.

\section{METHODS}

\section{Data sources}

We used anonymised primary care electronic health records from The Heath Improvement Network (THIN) in the UK. As of January 2018, 3.1 million patients were registered with a general practice contributing patient data to THIN, corresponding to approximately $5 \%$ of the UK general population. The data held are those entered by the primary care practitioner (PCP) as part of routine patient care, and include clinical, demographic and lifestyle information, and all prescriptions issued. The database has been validated for pharmacoepidemiology research and is representative of the UK demographic in terms of age, sex and geographical distribution. ${ }^{23} 24$

\section{Study population}

The study population included all patients aged $\geq 18$ years in THIN with a first prescription (index date) for apixaban, dabigatran or rivaroxaban (index NOAC) between 1 January 2012 and 31 December 2016. Although edoxaban has been recently licensed in the UK and recommended by The National Institute for Health and Care Excellence for stroke prevention in AF (June and September 2015, respectively) ${ }^{25} 26$ we did not expect widespread use of this NOAC during the study period and, therefore, did not include patients starting treatment on edoxaban in the study. Patients were required to have at least 1 year of computerised data before the index date. Patients were followed up for 1 year after the index date, and only patients with complete 1 year follow-up and at least two prescriptions for the index NOAC during this period were retained for analysis. To ensure our study population was patients with NVAF, individuals were required to have a record of AF (online supplementary table 1 ) but with no record of valvular replacement (online supplementary table 2) or mitral stenosis (online supplementary table 3) any time before the index date or within the 2 weeks after the index date. We also excluded patients with a record of deep vein thrombosis, pulmonary embolism or hip/knee replacement surgery (online supplementary table 4) in the 3 months before the index date or in the week after the index date because these indications are associated with different posology and durations of NOAC use.

\section{NOAC study cohorts}

Three mutually exclusive study cohorts were identified based on the index NOAC. Patients with a first prescription for two different NOACs on the same index date were excluded, and those who qualified as a first-time user of more than one NOAC during the study period (ie, they switched NOAC) were assigned to the cohort of the NOAC first prescribed. Patients with a prescription for a VKA before their index NOAC or a clinical entry implying previous use of a VKA, warfarin monitoring or international normalised ratio $>2$ were categorised as OAC non-naive, otherwise they were considered to be OAC-naïve.

\section{Patient characteristics}

We extracted data on patient demographics and lifestyle variables (body mass index (BMI), smoking status, alcohol consumption) using the most recent recorded value/status before the index date. We calculated patients' $\mathrm{CHA}_{2} \mathrm{DS}_{2}$ VASc Score for stroke risk (based on the recorded history of congestive heart failure, hypertension, age, diabetes mellitus, vascular disease, and stroke or transient ischaemic attack) and HAS-BLED Score for major bleeding risk (based on the recorded history of hypertension, renal disease, liver disease, stroke history, previous major bleeding, age $>65$ years, medication use predisposing to bleeding and alcohol use), but omitted international normalised ratio lability because this is not recorded for all patients in the database. Renal function was estimated using the closest valid serum creatinine value to the index date (within the year before) to estimated glomerular filtration rate (eGFR) expressed as $\mathrm{mL} / \mathrm{min} / 1.73 \mathrm{~m}^{2}$ applying the Chronic Kidney Disease Epidemiology Collaboration equation, ${ }^{27}$ but we omitted ethnicity because this is not systematically recorded in THIN. Patients with no recorded valid serum creatinine measurement were categorised as 'missing'. Frailty was estimated using a Frailty Index based on a wide range of symptoms, signs, diseases, disabilities, abnormal laboratory values and social circumstances developed for research using primary care databases, ${ }^{28}$ categorising 
patients as fit, mildly frail, moderately frail or severely frail.

\section{Follow-up and study outcomes}

Follow-up of the three NOAC cohorts stopped 1 year after the index date. Discontinuation of the index NOAC was defined as either a switch to another NOAC or to a VKA during the index NOAC treatment period or in the 30 days after, or if there was a gap in treatment of $>30$ days between an index NOAC prescription, if any (ie, between the end of an index NOAC prescription and the issue date of the next index NOAC prescription). Discontinuers who did not switch were categorised as reinitiators, and these were further divided according to whether they reinitiated treatment on the index NOAC, on a different NOAC, on a VKA or whether they stopped OAC treatment (non-reinitiators). All other patients were considered to be continuous users of their index NOAC during the first year of therapy. In a sensitivity analysis, we changed the definition of discontinuation to require a treatment gap of 60 days (allowing for greater non-adherence) to assess the effect this had on study outcomes.

\section{Statistical analysis}

For each NOAC cohort, we described baseline characteristics using frequency counts and percentages for categorical variables, and means with SD for continuous variables. Patients with missing data on smoking, alcohol consumption, BMI or renal function (eGFR) were not excluded from the analyses but were placed in a separate category 'missing' for that variable. To evaluate longitudinal patterns of NOAC use during the first year of treatment, we calculated the number and percentage of patients who continued/discontinued their initial NOAC therapy, switched, reinitiated (with the index NOAC, a different NOAC or a VKA), or stopped and did not reinitiate with any OAC therapy. Time to discontinuation and time to reinitiation, where appropriate, were calculated and expressed as mean time in days with SD and range (minimum to maximum). Kaplan-Meier survival analyses were performed to visualise the proportion of patients continuing treatment with the index NOAC during the 1 year follow-up period. Patient characteristics associated with the likelihood of index NOAC discontinuation (all discontinuers as well as separately for reinitiators, switchers and non-reinitiators) were identified using unconditional logistic regression to estimate ORs with 95\% CIs adjusted for confounders.

\section{Patient and public involvement}

This was a descriptive study using routinely collected primary care data in the UK. There was no public or patient involvement in the conception of the research question, the design and implementation of the study, or the writing of the manuscript.
RESULTS

\section{Baseline characteristics}

In total, there were 11481 patients with NVAF who were first-time NOAC users: 5889 (51.3\%) started on rivaroxaban, $3589(31.3 \%)$ on apixaban and $2003(17.4 \%)$ on dabigatran. Baseline characteristics of the three study cohorts are shown in table 1 . Mean age, obesity, smoking status, alcohol consumption, frailty, $\mathrm{CHA}_{2} \mathrm{DS}_{2}$ VASc Score and HAS-BLED Score were all comparable across cohorts. There were slightly more men than women in each cohort, and patients starting OAC therapy on apixaban were more likely to be OAC-naïve $(55.0 \%)$ compared with those starting on dabigatran $(44.0 \%)$ or rivaroxaban $(48.0 \%)$. Among all patients in the study, missing data were present as follows: BMI $(3.6 \%)$, smoking $(0.1 \%)$, alcohol consumption (9.6\%) and renal function (12.4\%).

\section{Patterns of NOAC use}

The percentage of patients who continued, switched, reinitiated, or stopped and did not reinitiate OAC therapy is shown in figure 1 and table 2 by study cohort while the proportion of patients continuing on the index NOAC during the 1 year follow-up period is shown in figure 2 . Within the first year of treatment the majority of patients in each cohort were continuous users of their initial NOAC; discontinuers accounted for $26.1 \%$ of the apixaban cohort, $40.0 \%$ of the dabigatran cohort and $29.6 \%$ of the rivaroxaban cohort. Some differences were seen in the percentage of patients discontinuing NOAC when restricting to those classified as OAC-naïve: apixaban $24.0 \%$, dabigatran $40.9 \%$ and rivaroxaban $28.9 \%$. In the sensitivity analysis (changing the definition of discontinuation to having a longer treatment gap of $>60$ days), the proportion of discontinuers was notably reduced: $13.5 \%$ for apixaban, $28.1 \%$ for dabigatran and $17.9 \%$ for rivaroxaban (online supplementary table 5 ).

Less than $10 \%$ of patients in each cohort stopped NOAC therapy and did not reinitiate OAC therapy. Around a fifth of patients in each cohort discontinued their initial NOAC therapy but reinitiated OAC treatment (after a gap in treatment of $>30$ days); the vast majority (at least $93 \%$ ) restarted on the index NOAC as opposed to another NOAC or a VKA: apixaban $97.7 \%$ (636/651), dabigatran 92.9\% (403/434) and rivaroxaban 95.0\% (970/1021). Only a small percentage of patients switched from their initial NOAC within 30 days of starting treatment, with a higher percentage of switchers seen in the dabigatran cohort $(8.8 \%)$ compared with apixaban $(2.8 \%)$ and rivaroxaban $(4.9 \%)$. As shown in table 2, more than half of switchers changed to a different NOAC rather than to a VKA $(53.0 \%(53 / 100))$ for patients starting on apixaban, compared with $64.2 \%(113 / 176)$ for dabigatran and $57.1 \%(165 / 289)$ for rivaroxaban.

\section{Time to discontinuation/reinitiation}

As shown in table 3 , among discontinuers, the mean time to index NOAC discontinuation was 4.7 months (SD 3.0), ranging from 1 day to just under a year, with minimal 
Table 1 Baseline characteristics of the three NOAC study cohorts

\begin{tabular}{|c|c|c|c|c|}
\hline & $\begin{array}{l}\text { Apixaban } \\
\mathrm{n}=3589\end{array}$ & $\begin{array}{l}\text { Dabigatran } \\
n=2003\end{array}$ & $\begin{array}{l}\text { Rivaroxaban } \\
\mathrm{n}=5889\end{array}$ & $\begin{array}{l}\text { Total } \\
n=11481\end{array}$ \\
\hline \multicolumn{5}{|l|}{ Sex } \\
\hline Male & $1931(53.8)$ & $1187(59.3)$ & $3280(55.7)$ & $6398(55.7)$ \\
\hline Female & $1658(46.2)$ & $816(40.7)$ & $2609(44.3)$ & $5083(44.3)$ \\
\hline \multicolumn{5}{|l|}{ Age (years) } \\
\hline$<60$ & $332(9.2)$ & $239(11.9)$ & $541(9.2)$ & $1112(9.7)$ \\
\hline $60-69$ & $776(21.6)$ & $459(22.9)$ & 1249 (21.2) & $2484(21.6)$ \\
\hline $70-79$ & $1201(33.5)$ & $713(35.6)$ & 2098 (35.6) & $4012(34.9)$ \\
\hline$\geq 80$ & $1280(35.7)$ & $592(29.6)$ & $2001(34.0)$ & $3873(33.7)$ \\
\hline Mean age (SD) & $74.2(10.7)$ & $72.9(10.7)$ & $71.7(14.4)$ & $74.0(10.6)$ \\
\hline \multicolumn{5}{|l|}{ OAC-naïve status } \\
\hline Naïve & $1973(55.0)$ & $881(44.0)$ & $2826(48.0)$ & $5680(49.5)$ \\
\hline Non-naïve & $1616(45.0)$ & $1122(56.0)$ & $3063(52.0)$ & $5801(50.5)$ \\
\hline \multicolumn{5}{|c|}{ Year of first NOAC prescription } \\
\hline 2011 & $0(0.0)$ & $40(2.0)$ & $2(0.0)$ & $42(0.4)$ \\
\hline 2012 & $0(0.0)$ & $444(22.2)$ & $196(3.3)$ & $640(5.6)$ \\
\hline 2013 & $186(5.2)$ & $704(35.1)$ & $984(16.7)$ & $1874(16.3)$ \\
\hline 2014 & $1171(32.6)$ & $494(24.7)$ & $1823(31.0)$ & $3488(30.4)$ \\
\hline 2015 & $2197(61.2)$ & 318 (15.9) & 2845 (48.3) & $5360(46.7)$ \\
\hline 2016 & $35(1.0)$ & $3(0.1)$ & $39(0.7)$ & $77(0.7)$ \\
\hline \multicolumn{5}{|l|}{$\mathrm{BMI}\left(\mathrm{kg} / \mathrm{m}^{2}\right)$} \\
\hline 10-19 & $124(3.5)$ & $62(3.1)$ & $216(3.7)$ & $402(3.5)$ \\
\hline $20-24$ & $810(22.6)$ & $435(21.7)$ & $1298(22.0)$ & $2543(22.1)$ \\
\hline $25-29$ & 1276 (35.6) & 737 (36.8) & 2078 (35.3) & 4091 (35.6) \\
\hline$\geq 30$ & $1248(34.8)$ & $697(34.8)$ & 2090 (35.5) & 4035 (35.1) \\
\hline Missing & $131(3.7)$ & $72(3.6)$ & 207 (3.5) & 410 (3.6) \\
\hline \multicolumn{5}{|l|}{ Smoking } \\
\hline Non-smoker & 1519 (42.3) & $844(42.1)$ & $2399(40.7)$ & $4762(41.5)$ \\
\hline Smoker & $286(8.0)$ & 147 (7.3) & 484 (8.2) & 917 (8.0) \\
\hline Ex-smoker & $1783(49.7)$ & $1010(50.4)$ & 3003 (51.0) & $5796(50.5)$ \\
\hline Missing & $1(0.0)$ & $2(0.1)$ & $3(0.1)$ & $6(0.1)$ \\
\hline \multicolumn{5}{|l|}{ Alcohol (units/week) } \\
\hline None & $851(23.7)$ & $330(16.5)$ & $1178(20.0)$ & 2359 (20.5) \\
\hline $1-9$ & $1544(43.0)$ & $894(44.6)$ & 2677 (45.5) & 5115 (44.6) \\
\hline $10-20$ & 578 (16.1) & $354(17.7)$ & 936 (15.9) & 1868 (16.3) \\
\hline $21-41$ & $195(5.4)$ & $160(8.0)$ & $367(6.2)$ & $722(6.3)$ \\
\hline$\geq 42$ & $83(2.3)$ & 67 (3.3) & $160(2.7)$ & $310(2.7)$ \\
\hline Missing & $338(9.4)$ & 198 (9.9) & $571(9.7)$ & $1107(9.6)$ \\
\hline \multicolumn{5}{|l|}{ Frailty index } \\
\hline Fit & 547 (15.2) & 346 (17.3) & $922(15.7)$ & 1815 (15.8) \\
\hline Mild frailty & 1338 (37.3) & 771 (38.5) & 2181 (37.0) & $4290(37.4)$ \\
\hline Moderate frailty & 1097 (30.6) & $576(28.8)$ & $1810(30.7)$ & $3483(30.3)$ \\
\hline Severe frailty & 607 (16.9) & $310(15.5)$ & 976 (16.6) & $1893(16.5)$ \\
\hline \multicolumn{5}{|c|}{ eGFR $\left(\mathrm{mL} / \mathrm{min} / 1.73 \mathrm{~m}^{2}\right)$} \\
\hline$>50$ & 2488 (69.3) & $1524(76.1)$ & $4260(72.3)$ & $8272(75.1)$ \\
\hline $30-50$ & $553(15.4)$ & 241 (12.0) & $826(14.0)$ & $1620(14.1)$ \\
\hline
\end{tabular}


Table 1 Continued

\begin{tabular}{|c|c|c|c|c|}
\hline & $\begin{array}{l}\text { Apixaban } \\
\mathrm{n}=3589\end{array}$ & $\begin{array}{l}\text { Dabigatran } \\
n=2003\end{array}$ & $\begin{array}{l}\text { Rivaroxaban } \\
\mathrm{n}=5889\end{array}$ & $\begin{array}{l}\text { Total } \\
n=11481\end{array}$ \\
\hline$<30$ & $75(2.1)$ & $11(0.6)$ & $84(1.4)$ & $170(1.5)$ \\
\hline \multicolumn{5}{|l|}{ CV/bleeding risk score } \\
\hline $\mathrm{CHA}_{2} \mathrm{DS}_{2}$ VASc, mean (SD) & $3.6(1.8)$ & $3.4(1.9)$ & $3.6(1.8)$ & $3.5(1.8)$ \\
\hline
\end{tabular}

Data are $\mathrm{n}(\%)$ unless otherwise specified.

$\mathrm{BMI}$, body mass index; CV, cardiovascular; eGFR, estimated glomerular filtration rate; NOAC, non-vitamin K oral anticoagulant; OAC, oral anticoagulant.

differences between NOAC cohorts. Discontinuers who did not later reinitiate any OAC therapy had a slightly longer time to discontinuation (mean 5.5 months) than those who later reinitiated OAC therapy (either on the same NOAC, a different NOAC or a VKA; mean 4.6 months) or who switched treatment (4.6 months). Among OAC reinitiators, no noticeable difference was seen in the time to reinitiation between the NOAC cohorts (apixaban 1.9 months, dabigatran 2.1 months and rivaroxaban 2.0 months) (online supplementary table 6 ).

\section{Predictors of discontinuation}

Associations between patient characteristics and discontinuation of NOAC therapy in the first year of treatment are shown in online supplementary table 7. Younger age, impaired renal function, lower $\mathrm{CHA}_{2} \mathrm{DS}_{2} \mathrm{VASc}$ Score and high alcohol consumption were associated with an increased likelihood of discontinuation. Compared with patients starting NOAC therapy on apixaban, those starting therapy on dabigatran were almost twice as likely to discontinue their treatment during the first year of treatment (adjusted OR 1.81, 95\% CI 1.59 to 2.07), while patients starting on rivaroxaban had a possible small increased likelihood of discontinuing their anticoagulation treatment (adjusted OR 1.18, 95\% CI 1.08 to 1.30). As shown by a breakdown of this analysis by type of discontinuers (vs continuers) (table 4), compared with patients starting on apixaban, those starting on dabigatran were four times more likely to switch OAC therapy (adjusted OR $4.28,95 \%$ CI 3.24 to 5.65 ), and those starting on

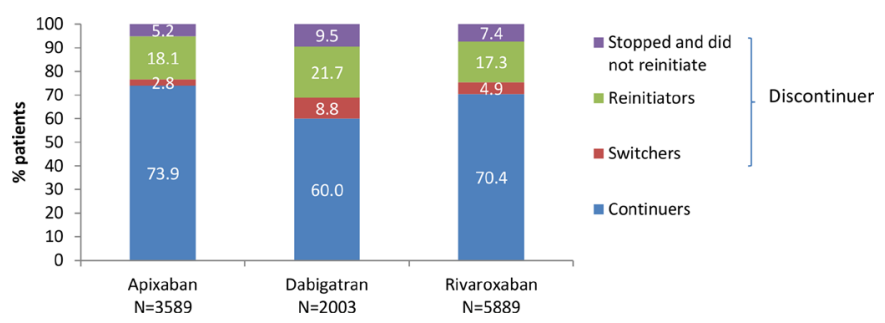

Figure 1 Patterns of NOAC use among first-time users of NOAC with NVAF (with >1 year of follow-up and using a 30-day treatment gap to define discontinuation). NOAC, non-vitamin K oral anticoagulant; NVAF, non-valvular atrial fibrillation. rivaroxaban were twice as likely to switch (adjusted OR $1.89,95 \%$ CI 1.49 to 2.39$)$. Having a reduced renal function $\left(<30 \mathrm{eGFR} \mathrm{ml} / \mathrm{min} / 1.73 \mathrm{~m}^{2}\right)$ was associated with all three kinds of treatment discontinuation (table 4).

\section{DISCUSSION}

Among patients with NVAF, continuation of NOAC therapy without interruption is important to gain the benefits of thromboembolic protection. In our study of 11481 patients with NVAF prescribed a NOAC for the first time in UK primary care, the majority had continued treatment with their initial prescribed NOAC during the first year of therapy, yet a substantial percentage experienced gaps in treatment of more than a month.

Our study is the largest to evaluate NOAC discontinuation rates among patients with NVAF in the UK, and the long study period including recent data enabled us to compare patterns of use between individual NOACs. Other strengths of our study include the large population-based sample of patients with NVAF from validated primary care databases representative of the UK population as a whole. Also, by including patients with or without previous OAC therapy use prior to starting NOAC therapy, we covered the whole spectrum of patients with NVAF prescribed NOACs. In terms of limitations, although most NOAC prescriptions are issued in primary care, those prescribed in secondary care may not have been captured, leading to a degree of misclassification of NOAC use. In addition, we were able to analyse prescriptions issued, but some may not have been subsequently dispensed from pharmacies and/or taken by the patient. Missing data on clinical and lifestyle variables were low and did not differ substantially between index NOAC discontinuers and continuers (only for renal function was there a slightly higher level of missing data among discontinuers), therefore this is unlikely to have impacted on the risk estimates to identify predictors of discontinuation. Another limitation of our study is the limited data available for patients whose index NOAC prescription was in 2016. This was due to the eligibility criterion of requiring a year of available follow-up data after the index date. 


\begin{tabular}{|c|c|c|c|c|}
\hline & $\begin{array}{l}\text { Apixaban } \\
n=3589\end{array}$ & $\begin{array}{l}\text { Dabigatran } \\
n=2003\end{array}$ & $\begin{array}{l}\text { Rivaroxaban } \\
\mathrm{n}=5889\end{array}$ & $\begin{array}{l}\text { Total } \\
n=11481\end{array}$ \\
\hline Switched within 30 days of the index date & $100(2.8)$ & $176(8.8)$ & $289(4.9)$ & 565 (4.9) \\
\hline Switched to a different NOAC & $53(1.5)$ & $113(5.6)$ & $165(2.8)$ & $331(2.9)$ \\
\hline Switched to a VKA & $47(1.3)$ & $63(3.1)$ & $124(2.1)$ & $234(2.0)$ \\
\hline Reinitiated ${ }^{\star}$ OAC therapy & $651(18.1)$ & $434(21.7)$ & $1021(17.3)$ & $2106(18.3)$ \\
\hline Reinitiated with the index NOAC & $636(17.7)$ & $403(20.1)$ & $970(16.5)$ & $2009(17.5)$ \\
\hline Reinitiated with a different NOAC & $8(0.2)$ & $14(0.7)$ & $21(0.4)$ & $43(0.4)$ \\
\hline Reinitiated with a VKA & $7(0.2)$ & $17(0.8)$ & $30(0.5)$ & $54(0.5)$ \\
\hline Stopped and did not reinitiate OAC therapy & $186(5.2)$ & $192(9.5)$ & $435(7.4)$ & $813(7.1)$ \\
\hline Total discontinuers & $937(26.1)$ & $802(40.0)$ & $1745(29.6)$ & $3484(30.3)$ \\
\hline
\end{tabular}

Data are $\mathrm{n}(\%)$.

${ }^{*}$ Restarted OAC therapy after a gap of $>30$ days between the end of the last prescription for the index NOAC and the next prescription for an OAC.

NOAC, non-vitamin K antagonist oral anticoagulant; NVAF, non-valvular atrial fibrillation; OAC, oral anticoagulant; VKA, vitamin K antagonist .

We are aware of only two previous UK studies in this area, both using electronic primary care data and among OAC-naïve patients. ${ }^{12} 13$ In a study of 2871 patients with NVAF, Johnson $e t a l^{13}$ reported broadly similar, although slightly higher, 1-year NOAC discontinuation rates to those found in our study using a 60-day treatment gap, with rates highest for dabigatran $(33.3 \%)$ followed by rivaroxaban $(26.9 \%)$ and apixaban $(17.2 \%)$. A smaller study by Martinez et $a l^{12}$ reported much lower NOAC discontinuation rates to ours ( $17 \%$ at 1 year) with apixaban unable to be assessed due to short duration of available follow-up (apixaban was recommended by the UK National Institute for Health and Care Excellence guidelines a year later than for dabigatran and rivaroxaban) ${ }^{29-31}$ Studies from other European countries have reported either highly comparable, ${ }^{32}$ notably higher ${ }^{17}$ or lower ${ }^{15} 18$-year NOAC discontinuation rates based on a 30-day treatment gap, ${ }^{18} 60$-day treatment gap ${ }^{1732}$ or other definition of discontinuation, ${ }^{15}$ with differences possibly attributable to differences in study size, design and/or

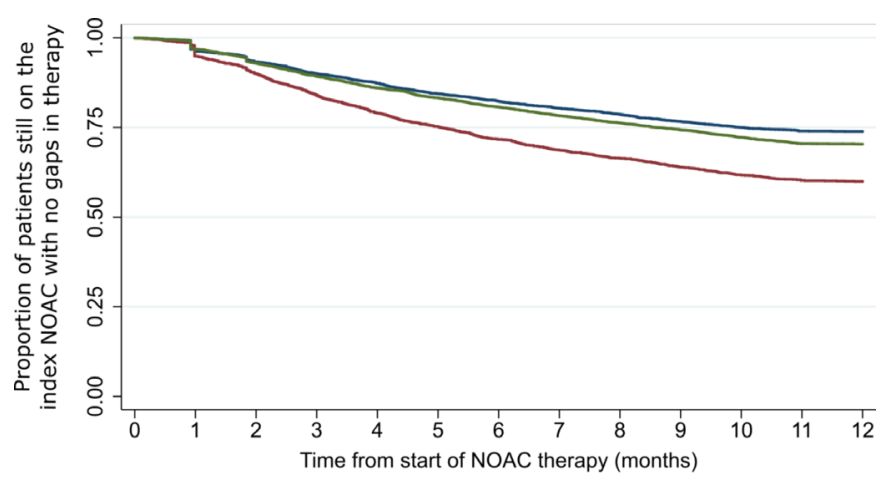

- Apixaban Rivaroxaban Dabigatran

Figure 2 Kaplan-Meier plot showing time to NOAC discontinuation. NOAC, non-vitamin $\mathrm{K}$ antagonist oral anticoagulant. composition of the study population (eg, the inclusion of OAC-naïve users only). One-year NOAC discontinuation rates among patient populations with NVAF reported from claims database studies in USA have been substantially higher, ${ }^{21}{ }^{33}$ yet are consistent with a trend of higher discontinuation for dabigatran compared with rivaroxaban or apixaban, ${ }^{13} 151721223233$ and of rates lowest for apixaban in most, ${ }^{1315172133}$ although not all, ${ }^{22}$ studies. Most other studies on NOAC discontinuation have reported rates over shorter time periods. ${ }^{34}$

In our present study, after controlling for differences in patient characteristics (such as lifestyle factors, $\mathrm{CHA}_{2} \mathrm{DS}_{2 \text { - }}$ VASc Score, HAS-BLED Score and Frailty Index) between NOAC cohorts, patients starting OAC therapy on rivaroxaban had only a small increased likelihood of discontinuing treatment, while those starting on dabigatran were twice as likely to discontinue, when compared with those starting on apixaban. This is in line with findings from other studies among American and European OAC-naive NVAF cohorts, ${ }^{131521}$ but contrasts with those reported by McHorney $e t a l^{22}$ in USA, who found that among 23 309 patients with NVAF starting NOAC therapy, patients treated with rivaroxaban were significantly less likely to discontinue therapy at 1 year, as well as at earlier time points, compared with those starting on apixaban or dabigatran. It should be noted that the higher level of discontinuation seen for dabigatran, both in our study and in others, could be partially explained by its longer market availability. Being the first NOAC to be introduced for stroke prevention in AF would mean that patients who started on dabigatran had greater opportunity to switch to a different (newer) NOAC as these became available. This is clearly shown by our finding that patients starting on dabigatran were four times more likely to switch OAC in the first month of therapy than patients starting on apixaban. Only $7 \%$ of patients with NVAF in our study 
Table 3 Time to discontinuation of NOAC therapy among patients with NVAF who discontinued their initial prescribed NOAC (index NOAC)

\begin{tabular}{lccc}
\hline & \multicolumn{3}{c}{ Time to discontinuation* (months) } \\
\cline { 3 - 4 } & N & $\begin{array}{l}\text { Mean } \\
\text { (months; SD) }\end{array}$ & $\begin{array}{l}\text { Range } \\
\text { (days, min-max) }\end{array}$ \\
\hline Among discontinuers by index NOAC & & & \\
$\quad$ Apixaban & 937 & $4.7(3.0)$ & $3-356$ \\
$\quad$ Dabigatran & 802 & $4.5(3.0)$ & $2-361$ \\
$\quad$ Rivaroxaban & 1745 & $4.9(3.1)$ & $1-363$ \\
Among discontinuers by type of discontinuation & & & \\
Any NOAC: switchers & 565 & $4.0(3.0)$ & $1-363$ \\
Any NOAC: discontinued and reinitiated† & 2106 & $4.6(2.9)$ & $5-334$ \\
Any NOAC: stopped and did not restart any OAC therapy & 813 & $5.5(3.2)$ & $10-334$ \\
\hline Total (all NOACs) & $\mathbf{3 4 8 4}$ & $4.7(3.0)$ & $\mathbf{1 - 3 6 3}$ \\
\hline
\end{tabular}

*Among patients who discontinued treatment with their index NOAC-had a break in treatment of $>30$ days between consecutive index NOAC prescriptions (ie, between the end of supply of an index NOAC prescription and the date of the subsequent index NOAC prescription), or if they switched to another NOAC or a VKA during the treatment period with the index NOAC or within 30 days after the end of supply of the index NOAC prescription.

†Reinitiated with either the same NOAC, a different NOAC or with a VKA.

NOAC, non-vitamin-K antagonist oral anticoagulant; NVAF, non-valvular atrial fibrillation; OAC, oral anticoagulant; VKA, vitamin K antagonist.

permanently discontinued NOAC therapy, which is approximately half the rate seen in Italy ${ }^{35}$ and approximately a third of that seen for rivaroxaban in Germany, ${ }^{18}$ and this may be a reflection of the growing confidence of both physicians and patients about long-term use of NOACs.

As seen in Sweden, ${ }^{15}$ we found that the vast majority of NOAC reinitiators in our study restarted with the index NOAC. Similarly, only a small proportion of patients $(<5 \%)$ switched to another NOAC or a VKA, with more than half switching to a different NOAC. These findings suggest good tolerability and confidence in this class of medication in the UK. Comparable NOAC switching rates have been reported in two large US claims database studies ${ }^{1433}$ while in another large US administrative database among 34022 OAC-naïve patients with NVAF, nearly $20 \%$ switched medication. ${ }^{36}$ Switching rates among other European NVAF cohorts starting NOAC therapy have been notably higher. In particular, using national healthcare databases in France, Maura $e t a \vec{l}^{2}$ found that $9.8 \%$ of patients starting rivaroxaban therapy switched to another OAC class, while in the UK, Martinez et $a l^{12}$ reported a $6.6 \%$ NOAC-to-VKA switch rate.

We did not analyse reasons for discontinuation or switching in our study as this was beyond the scope of this study and these reasons are included in the free text comments entered by PCPs in THIN, which we did not access. In the study by Martinez et al, ${ }^{12}$ among 914 UK patients with NVAF initiating NOAC therapy, 7 (0.8\%) discontinued because of a bleeding event, while in Germany, $30 \%$ of all rivaroxaban discontinuations were due to bleeding complications, $24 \%$ due to side effects and $10 \%$ because of a diagnosis of stable sinus rhythm. In a nationwide registry-based study in Denmark of 5206 patients with NVAF, $7.6 \%$ of patients who discontinued did so because of bleeding, while about quarter of both discontinuations and of NOAC-to-VKA switches were preceded by hospitalisation for a specific clinical event or procedure, cardioversion being the most common reason. ${ }^{37}$ Cardioversion is another possible explanation for the higher discontinuation rate among patients starting NOAC therapy with dabigatran, having been approved for use in this patient population earlier. ${ }^{38-41}$

Identifying patients more likely to discontinue NOAC therapy may help target those for counselling regarding persistence with treatment, and our current findings suggest that these might include patients at younger age when starting NOAC therapy as well as those with impaired renal function and lower $\mathrm{CHA}_{2} \mathrm{DS}_{2}$ VASc Score. Observational data suggest that interruption of warfarin treatment in patients with $\mathrm{AF}$ is associated with an increased risk of thromboembolism, ${ }^{38}$ as is poor adherence to NOACs. ${ }^{39}{ }^{40}$ Evaluating adherence in our study population was beyond the scope of this individual study, yet is an area for future study in order to compare with the existing wide-ranging findings on this topic. ${ }^{34}$ Studies are now needed to quantify the impact of interrupted NOAC therapy, including the length of interruption, on the risk of stroke and other thromboembolic events in well-designed large cohort studies. Efforts are also needed to increase uninterrupted and continued NOAC use in order to increase the number of patients with NVAF benefiting from NOAC-mediated stroke protection.

\section{CONCLUSION}

In conclusion, while the majority of patients with NVAF in the UK initiating NOAC treatment received continuous 
Table 4 Associations between baseline characteristics of patients with NVAF (new users of a NOAC) and risk of discontinuation according to type of discontinuation

\begin{tabular}{|c|c|}
\hline $\begin{array}{l}\text { Continuers }(n=7997) \\
\text { versus discontinuers who } \\
\text { reinitiated OAC therapy } \\
(n=2106)\end{array}$ & $\begin{array}{l}\text { Continuers }(n=7997) \\
\text { versus discontinuers who } \\
\text { switched OAC therapy } \\
(n=565)\end{array}$ \\
\hline
\end{tabular}

Continuers $(\mathrm{n}=7997)$ versus discontinuers who did not reinitiate OAC therapy

Adjusted OR* $(95 \% \mathrm{Cl}) \quad$ Adjusted OR* $(95 \% \mathrm{Cl}) \quad$ Adjusted OR* $(95 \% \mathrm{Cl})$

Sex

$\begin{array}{llll}\text { Male } & 1.0 \text { (reference) } & 1.0 \text { (reference) } & 1.0 \text { (reference) } \\ \text { Female } & 0.89(0.79 \text { to } 0.99) & 1.25(1.03 \text { to } 1.53) & 0.90(0.76 \text { to } 1.07)\end{array}$

Age (years)

$\begin{array}{llll}<60 & 1.0 \text { (reference) } & 1.0 \text { (reference) } & 1.0 \text { (reference) } \\ 60-69 & 0.74(0.62 \text { to } 0.90) & 0.95(0.66 \text { to } 1.37) & 0.33(0.26 \text { to } 0.43) \\ 70-79 & 0.74(0.61 \text { to } 0.90) & 0.93(0.63 \text { to } 1.36) & 0.27(0.21 \text { to } 0.36) \\ \geq 80 & 0.72(0.58 \text { to } 0.89) & 0.68(0.45 \text { to } 1.03) & 0.35(0.26 \text { to } 0.48)\end{array}$

Index NOAC

Apixaban

1.0 (reference)

1.0 (reference)

1.0 (reference)

Dabigatran

1.36 (1.16 to 1.60$)$

4.28 (3.24 to 5.65$)$

2.19 (1.72 to 2.79 )

Rivaroxaban

0.98 (0.87 to 1.09$)$

1.89 (1.49 to 2.39 )

1.52 (1.26 to 1.83$)$

Year of first NOAC prescription

2011-2013

1.0 (reference)

1.0 (reference)

1.0 (reference)

2014-2016

0.90 (0.79 to 1.02$)$

1.21 (0.97 to 1.50$)$

0.82 (0.68 to 0.99 )

eGFR (mL/min/1.73 $\left.\mathrm{m}^{2}\right)$

$\begin{array}{llll}>50 & 1.0 \text { (reference) } & 1.0 \text { (reference) } & 1.0 \text { (reference) } \\ 30-50 & 1.08(0.93 \text { to } 1.26) & 1.23(0.95 \text { to } 1.59) & 1.53 \text { (1.22 to } 1.91) \\ <30 & 1.51(1.01 \text { to } 2.25) & 2.21(1.20 \text { to } 4.08) & 2.25(1.30 \text { to } 3.87) \\ \text { Missing } & 1.31(1.13 \text { to } 1.51) & 1.28(0.98 \text { to } 1.67) & 1.30 \text { (1.05 to } 1.62)\end{array}$

OAC-naïve status

$\begin{array}{llll}\text { Naïve } & 1.0 \text { (reference) } & 1.0 \text { (reference) } & 1.0 \text { (reference) } \\ \text { Non-naïve } & 1.08(0.97 \text { to } 1.19) & 1.25(1.04 \text { to } 1.50) & 0.74 \text { (0.64 to } 0.87)\end{array}$

BMI $\left(\mathrm{kg} / \mathrm{m}^{2}\right)$

\begin{tabular}{|c|c|c|c|}
\hline$<20$ & 0.98 (0.74 to 1.31$)$ & 0.85 (0.50 to 1.44$)$ & $1.26(0.86$ to 1.85$)$ \\
\hline $20-24$ & 1.0 (reference) & 1.0 (reference) & 1.0 (reference) \\
\hline $25-29$ & 0.94 (0.82 to 1.07$)$ & 1.01 (0.80 to 1.28$)$ & 0.90 (0.74 to 1.09$)$ \\
\hline$\geq 30$ & 0.89 (0.77 to 1.02$)$ & 0.78 (0.61 to 1.00$)$ & 0.67 (0.54 to 0.83 ) \\
\hline Missing & 0.94 (0.70 to 1.25$)$ & 0.99 (0.58 to 1.69$)$ & 1.37 (0.94 to 2.01$)$ \\
\hline \multicolumn{4}{|l|}{ Smoking } \\
\hline Non-smoker & 1.0 (reference) & 1.0 (reference) & 1.0 (reference) \\
\hline Smoker & 0.99 (0.82 to 1.19$)$ & 0.64 (0.43 to 0.96$)$ & 0.83 (0.62 to 1.10$)$ \\
\hline Ex-smoker & 0.96 (0.86 to 1.07$)$ & $1.08(0.90$ to 1.30$)$ & 0.95 (0.81 to 1.12$)$ \\
\hline Missing & 2.47 (0.40 to 15.21$)$ & - & 1.42 (0.11 to 18.04$)$ \\
\hline \multicolumn{4}{|c|}{ Alcohol (units/week) } \\
\hline None & 1.0 (reference) & 1.0 (reference) & 1.0 (reference) \\
\hline $1-9$ & 1.03 (0.90 to 1.18$)$ & $1.13(0.89$ to 1.43$)$ & 0.87 (0.71 to 1.06$)$ \\
\hline 10-20 & 1.13 (0.95 to 1.33$)$ & 0.92 (0.67 to 1.26$)$ & 1.11 (0.86 to 1.43$)$ \\
\hline $21-41$ & 1.19 (0.95 to 1.49$)$ & 1.32 (0.89 to 1.96$)$ & 0.85 (0.59 to 1.22$)$ \\
\hline$\geq 42$ & 1.75 (1.30 to 2.35$)$ & 1.10 (0.58 to 2.08$)$ & 1.24 (0.77 to 1.99$)$ \\
\hline Missing & 1.12 (0.92 to 1.36$)$ & 0.93 (0.65 to 1.34$)$ & 0.77 (0.57 to 1.05$)$ \\
\hline
\end{tabular}




\begin{tabular}{|c|c|c|}
\hline $\begin{array}{l}\text { Continuers }(n=7997) \\
\text { versus discontinuers who } \\
\text { reinitiated OAC therapy } \\
(n=2106)\end{array}$ & $\begin{array}{l}\text { Continuers }(n=7997) \\
\text { versus discontinuers who } \\
\text { switched OAC therapy } \\
(n=565)\end{array}$ & $\begin{array}{l}\text { Continuers }(n=7997) \text { versus } \\
\text { discontinuers who did not } \\
\text { reinitiate OAC therapy } \\
(n=813)\end{array}$ \\
\hline Adjusted OR* (95\% CI) & Adjusted OR* (95\% Cl) & Adjusted OR* (95\% Cl) \\
\hline
\end{tabular}

Frailty index

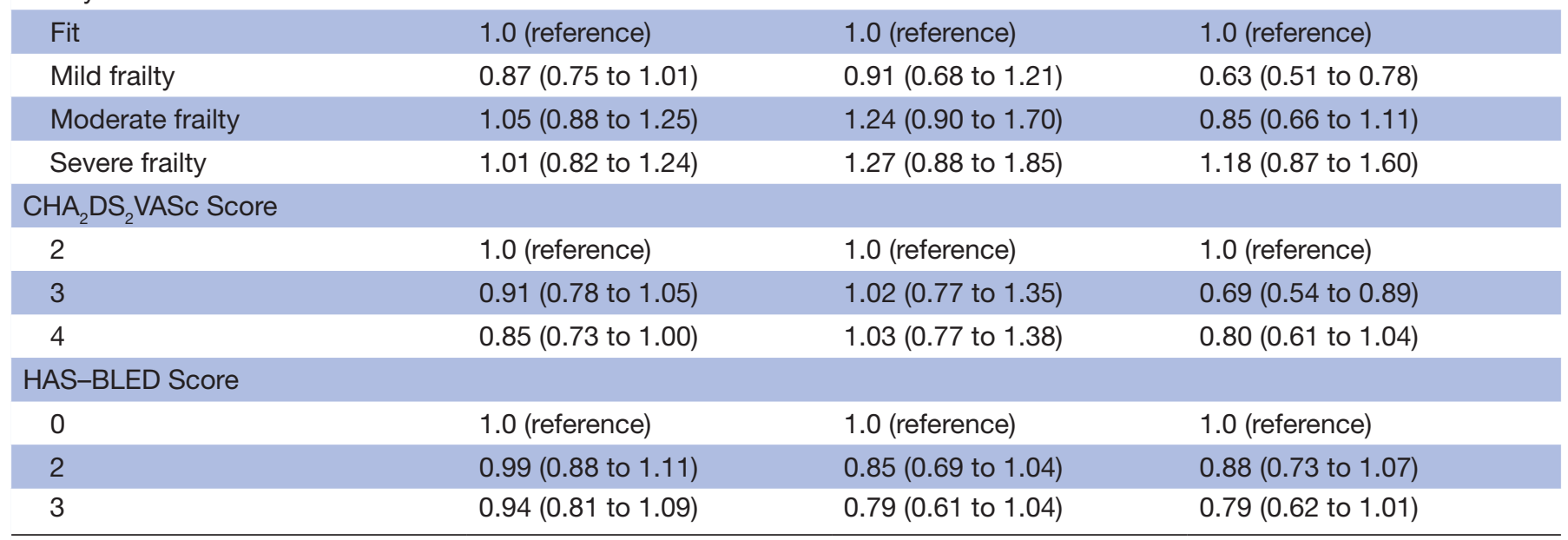

*Adjusted for all the other variables in the table.

BMI, body mass index; eGFR, estimated glomerular filtration rate; NOAC, non-vitamin K antagonist oral anticoagulant; NVAF, non-valvular atrial fibrillation; OAC, oral anticoagulant.

therapy in the first year of treatment, a substantial proportion of patients experience gaps in treatment leaving them less protected against thromboembolism during these periods.

\section{Author affiliations}

${ }^{1}$ Pharmacoepidemiology, Spanish Centre for Pharmacoepidemiological Research, Madrid, Spain

${ }^{2}$ Epidemiology, Bayer AG, Berlin, Germany

${ }^{3}$ Epidemiology, Bayer AB, Stockholm, Sweden

${ }^{4}$ Study Medical Experts, Bayer plc, Reading, UK

${ }^{5}$ Medical Affairs, Bayer plc, Reading, UK

Acknowledgements The authors thank Susan Bromley, EpiMed Communications Ltd (Oxford, UK) for medical writing assistance funded by Bayer AG.

Contributors LR and SF developed the concept for the research study. LR, SF, LAGR, AR, GB, PV, and YB planned the study. AR, LAGR and OF conducted the study. All authors interpreted the data, reviewed drafts of the manuscript, and approved the final version of the article for publication.

Funding This work was supported by Bayer AG. PV and YB (both employees of Bayer $A G$ ) were involved in the study conception, data interpretation, and the review of manuscript drafts. The funder had no role in the study design, or in the collection or analysis of data.

Competing interests LAGR, OF and AR work for the Spanish Centre for Pharmacoepidemiologic Research (Madrid, Spain), which has received research funding from Bayer AG. LAGR also declares honoraria for serving on advisory boards for Bayer $A G$. PV and $Y B$, are employees of Bayer $A G$ (Germany), the funder of the study; GB is an employee of Bayer AB, (Stockholm, Sweden); LR and SF are employees of Bayer PLC (Reading, UK). LR and SF declare shares in Bayer.

Patient consent for publication Not required.

Ethics approval The study protocol was approved by the Independent Scientific Research Committee for THIN (reference SRC 17THIN014). Data collection for THIN was approved by the South East Multicentre Research Ethics Committee in 2003 and individual studies using THIN data do not require separate ethical approval if only anonymised THIN data are used.

Provenance and peer review Not commissioned; externally peer reviewed.

Data availability statement Data are available from the corresponding author upon reasonable request.

Open access This is an open access article distributed in accordance with the Creative Commons Attribution Non Commercial (CC BY-NC 4.0) license, which permits others to distribute, remix, adapt, build upon this work non-commercially, and license their derivative works on different terms, provided the original work is properly cited, appropriate credit is given, any changes made indicated, and the use is non-commercial. See: http://creativecommons.org/licenses/by-nc/4.0/.

\section{REFERENCES}

1 Kirchhof $P$. The future of atrial fibrillation management: integrated care and stratified therapy. The Lancet 2017;390:1873-87.

2 Kirchhof P, Benussi S, Kotecha D, et al. Esc guidelines for the management of atrial fibrillation developed in collaboration with EACTS. Eur Heart J 2016;2016:2893-962.

3 Nice implementation collaborative. consensus: supporting local implementation of NICE guidance on use of the novel (non-vitamin K antagonist) oral anticoagulants in non-valvular atrial fibrillation.

4 National Institute for Health and Care Excellence. Atrial fibrillation: management. clinical guideline. Available: nice.org.uk/guidance/ cg180 [Accessed 18 Jun 2014].

5 Loo SY, Dell'Aniello S, Huiart L, et al. Trends in the prescription of novel oral anticoagulants in UK primary care. Br J Clin Pharmacol 2017;83:2096-106

6 Vinogradova Y, Coupland C, Hill T, et al. Risks and benefits of direct oral anticoagulants versus warfarin in a real world setting: cohort study in primary care. BMJ 2018;362.

7 European medicines Agency. Eliquis. summary of product characteristics. Available: http://www.ema.europa.eu/docs/en_GB/ document_library/EPAR___Product_Information/human/002148/ WC500107728.pdf [Accessed 7 Sep 2018].

8 European medicines Agency. Xarelto. summary of product characteristics. Available: http://www.ema.europa.eu/docs/en_GB/ 
document_library/EPAR_-_Product_Information/human/000944/ WC500057108.pdf

9 Rivera-Caravaca JM, Esteve-Pastor MA, Roldán V, et al. Non-Vitamin $\mathrm{K}$ antagonist oral anticoagulants: impact of non-adherence and discontinuation. Expert Opin Drug Saf 2017;16:1051-62.

10 Jackevicius CA, Tsadok MA, Essebag V, et al. Early non-persistence with dabigatran and rivaroxaban in patients with atrial fibrillation. Heart 2017;103:1331-8.

11 Bauer KA. Pros and cons of new oral anticoagulants. Hematology 2013;2013:464-70.

12 Martinez C, Katholing A, Wallenhorst C, et al. Therapy persistence in newly diagnosed non-valvular atrial fibrillation treated with warfarin or NOAC. A cohort study. Thromb Haemost 2016;115:31-9.

13 Johnson ME, Lefèvre C, Collings S-L, et al. Early real-world evidence of persistence on oral anticoagulants for stroke prevention in nonvalvular atrial fibrillation: a cohort study in UK primary care. BMJ Open 2016:6:e011471.

14 Brown JD, Shewale AR, Talbert JC. Adherence to rivaroxaban, dabigatran, and apixaban for stroke prevention for newly diagnosed and treatment-naive atrial fibrillation patients: an update using 20132014 data. J Manag Care Spec Pharm 2017;23:958-67.

15 Forslund T, Wettermark B, Hjemdahl P. Comparison of treatment persistence with different oral anticoagulants in patients with atrial fibrillation. Eur J Clin Pharmacol 2016;72:329-38.

16 Lefevre C, Benhaddi H, Lacoin L, et al. Persistence to vitamin-K antagonists (Vka) and novel oral anticoagulants (NOACs) in NonValvular atrial fibrillation (Nvaf): an observational study using a comprehensive regional database in Catalonia, Spain. Value in Health 2015;18.

17 Collings S-L, Lefèvre C, Johnson ME, et al. Oral anticoagulant persistence in patients with non-valvular atrial fibrillation: a cohort study using primary care data in Germany. PLoS One 2017;12:e0185642.

18 Beyer-Westendorf J, Forster K, Ebertz F, et al. Drug persistence with rivaroxaban therapy in atrial fibrillation patients--results from the Dresden non-interventional oral anticoagulation registry. Europace 2015;17:530-8.

19 Gomez-Lumbreras A, Cortes J, Giner-Soriano M, et al. Characteristics of Apixaban-Treated patients, evaluation of the dose prescribed, and the persistence of treatment: a cohort study in Catalonia. J Cardiovasc Pharmacol Ther 2018;23:494-501.

20 Coleman $\mathrm{Cl}$, Tangirala M, Evers T. Treatment persistence and discontinuation with rivaroxaban, dabigatran, and warfarin for stroke prevention in patients with Non-Valvular atrial fibrillation in the United States. PLoS One 2016;11:e0157769.

21 Lip GYH, Pan X, Kamble S, et al. Discontinuation risk comparison among 'real-world' newly anticoagulated atrial fibrillation patients: Apixaban, warfarin, dabigatran, or rivaroxaban. PLoS One 2018;13:e0195950.

22 McHorney CA, Ashton V, Laliberté F, et al. Adherence to rivaroxaban compared with other oral anticoagulant agents among patients with nonvalvular atrial fibrillation. J Manag Care Spec Pharm 2017;23:980-8.

23 Lewis JD, Schinnar R, Bilker WB, et al. Validation studies of the health improvement network (thin) database for pharmacoepidemiology research. Pharmacoepidemiol Drug Saf 2007;16:393-401.

24 Blak B, Thompson M, Dattani H, et al. Generalisability of the health improvement network (thin) database: demographics, chronic disease prevalence and mortality rates. Jhi 2011;19:251-5.

25 European medicines Agency. Lixiana. summary of product characteristics. Available: http://www.ema.europa.eu/docs/en_GB/
document_library/EPAR_-_Product_Information/human/002629/ WC500189045.pdf

26 National Institute for Health and Care Excellence. Edoxaban for preventing stroke and systemic embolism in people with nonvalvular atrial fifibrillation. technology appraisal guidance. Available: niceorguk/guidance/ta355 [Accessed 23 Sep 2015].

27 Levey AS, Stevens LA, Schmid CH, et al. A new equation to estimate glomerular filtration rate. Ann Intern Med 2009;150:604-12.

28 Clegg A, Bates C, Young J, et al. Development and validation of an electronic frailty index using routine primary care electronic health record data. Age Ageing 2016;45:353-60.

29 National Institute for Health and Care Excellence. Dabigatran etexilate for the preventionof stroke and systemic embolism in atrial fibrillation. technology appraisal guidance. Available: niceorguk/ guidance/ta249@ [Accessed 15 Mar 2012].

30 National Institute for Health and Care Excellence. Rivaroxaban for the prevention of stroke and systemic embolism in people with atrial fifibrillation technology appraisal guidance. Available: niceorguk/ guidance/ta256(C) [Accessed 23 may 2012].

31 National Institute for Health and Care Excellence. Apixaban for preventing stroke and systemic embolism in people with nonvalvular atrial fifibrillation. technology appraisal guidance. Available: niceorguk/guidance/ta275 [Accessed 27 Feb 2013].

32 Maura G, Billionnet C, Alla F, et al. Comparison of treatment persistence with dabigatran or rivaroxaban versus vitamin $\mathrm{K}$ antagonist oral anticoagulants in atrial fibrillation patients: a competing risk analysis in the French National health care databases. Pharmacotherapy 2018;38:6-18.

33 Baker CL, Dhamane AD, Mardekian J, et al. Comparison of drug switching and discontinuation rates in patients with nonvalvular atrial fibrillation treated with direct oral anticoagulants in the United States. Adv Ther 2019;36:162-74.

34 Raparelli V, Proietti M, Cangemi R, et al. Adherence to oral anticoagulant therapy in patients with atrial fibrillation. focus on non-vitamin $\mathrm{K}$ antagonist oral anticoagulants. Thromb Haemost 2017:117:209-8.

35 Vedovati MC, Verdecchia P, Giustozzi M, et al. Permanent discontinuation of non vitamin $\mathrm{K}$ oral anticoagulants in real life patients with non-valvular atrial fibrillation. Int $J$ Cardiol 2017;236:363-9.

36 Manzoor BS, Walton SM, Sharp LK, et al. High number of newly initiated direct oral anticoagulant users switch to alternate anticoagulant therapy. J Thromb Thrombolysis 2017;44:435-41.

37 Hellfritzsch M, Grove EL, Husted SE, et al. Clinical events preceding switching and discontinuation of oral anticoagulant treatment in patients with atrial fibrillation. Europace 2017;19:1091-5.

38 Hohnloser SH, Eikelboom JW. The hazards of interrupting anticoagulation therapy in atrial fibrillation. Eur Heart $J$ 2012;33:1864-6.

39 Borne RT, O'Donnell C, Turakhia MP, et al. Adherence and outcomes to direct oral anticoagulants among patients with atrial fibrillation: findings from the Veterans health administration. BMC Cardiovasc Disord 2017;17:236

40 Deshpande CG, Kogut S, Laforge R, et al. Impact of medication adherence on risk of ischemic stroke, major bleeding and deep vein thrombosis in atrial fibrillation patients using novel oral anticoagulants. Curr Med Res Opin 2018;34:1285-92.

41 Ezekowitz MD, Pollack CV, Halperin JL, et al. Apixaban compared to heparin/vitamin $\mathrm{K}$ antagonist in patients with atrial fibrillation scheduled for cardioversion: the EMANATE trial. Eur Heart $J$ 2018;39:2959-71. 
Correction: Discontinuation of non-Vitamin K antagonist oral anticoagulants in patients with non-valvular atrial fibrillation: a population-based cohort study using primary care data from The Health Improvement Network in the UK

Ruigómez A, Vora P, Balabanova Y, et al. Discontinuation of non-Vitamin K antagonist oral anticoagulants in patients with non-valvular atrial fibrillation: a population-based cohort study using primary care data from The Health Improvement Network in the UK. BMJ Open 2019;9:e031342. doi: 10.1136/bmjopen-2019-031342.

This article was previously published with an error.

In table 1 , the mean age of patients in the Rivaroxaban column should read 74.3 (10.5) and not 71.7 (14.4).

Open access This is an open access article distributed in accordance with the Creative Commons Attribution Non Commercial (CC BY-NC 4.0) license, which permits others to distribute, remix, adapt, build upon this work non-commercially, and license their derivative works on different terms, provided the original work is properly cited, appropriate credit is given, any changes made indicated, and the use is non-commercial. See: http://creativecommons.org/licenses/by-nc/4.0/.

(c) Author(s) (or their employer(s)) 2020. Re-use permitted under CC BY-NC. No commercial re-use. See rights and permissions. Published by BMJ.

BMJ Open 2020;10:e031342corr1. doi:10.1136/bmjopen-2019-031342corr1

Check for updates 